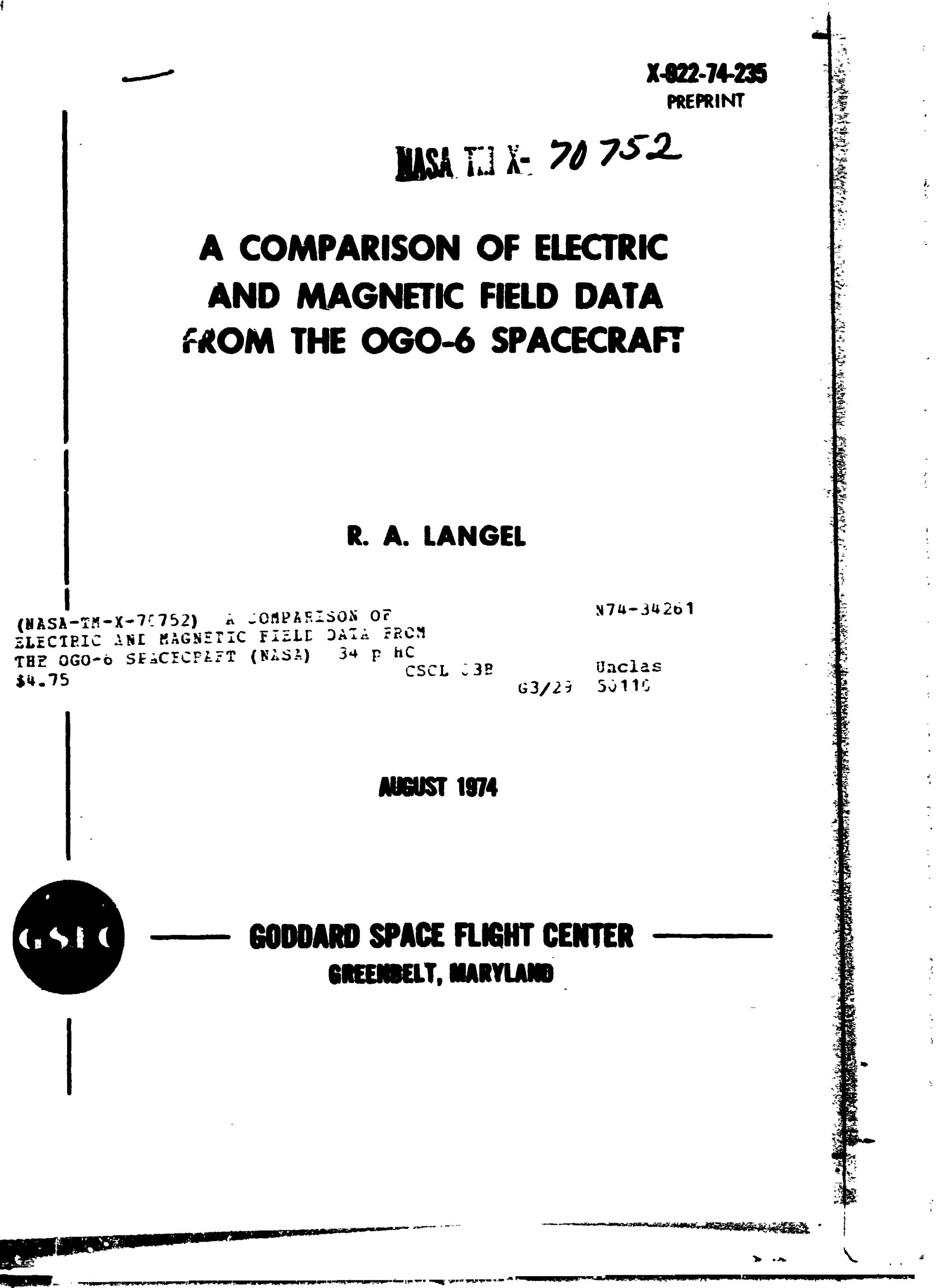


$\mathrm{X}-922-74-235$

\section{A COMPARISON OF ELECTRIC AND MAGNETIC FIELD \\ DATA FROM THE OGO-6 SPACECRAFT}

R. A. Langel

Geophysics Branch

GODDARD SPACE FLIGHT CENTER

Greenbelt, Md. 20771 
A COMPARISON OF ELECTRIC AND MAGNETIC FIELD

DATA FROM THE OGO-6 SPACECRAFT

R. A. Langel

Geophysics Branch

Goddard Space Flight Center

Greenbelt, Maryland 20771 


\section{ABSTRACT}

Previous studies of the OGO-6 electric field data by Heppner and of magnetic field magnitude observations by Langel have indicated a distinct dependence of disturbance characteristics on interplanetary sector polarity. Examination of simultaneous patterns of disturbance below $600 \mathrm{~km}$ over the summer polar cap shows that pattern changes in electric field and in the disturbance in magnetic field magnitude are highly correlated. This correlation extends to pattern shapes, boundary locations, and to the amplitudes of the corselated quantities. In the winter hemisphere, at altitudes above $800 \mathrm{~km}$, correlations between boundaries exist, pattern correlations are present but are not as strong as at low altitudes in summer, and amplitude correlations are essentially absent. These studies verify that below $600 \mathrm{~km}$ the region of positive $J \mathrm{~B}$, from 2200 to $1000 \mathrm{MLT}$, has a significant contribution from both ionospheric and non-ionospheric sources. Above $800 \mathrm{~km}$ the non-ionospheric sources dominate. These data also are consistent with the existence of a latitudinaliy broad current system at sunlit MLT as the source of the negative $\triangle B$ region between 1000 and 2200 MLT. In this region broad structures in electric field patterns and in $\Delta B$ patterns are highly correlated. Multiple peaks in the negative $\Delta B$, presumably to be identified with the multiple peaks in negative $\Delta Z$ found by Langel (1973) in average surface data, occur when the electric fleld pattern has multiple reversals near dusk. Pattern variability is large enough so that it is probably not meaningful to draw equivalent current systems. 
CONTENTS

$\underline{\text { Page }}$

ABSTRACT......................... iii

SIGNATURE CORRELATION ...................... 4

AMPLITUDE CORRELATIONS ................... 11

Discussion $\ldots \ldots \ldots \ldots \ldots \ldots \ldots \ldots \ldots \ldots \ldots \ldots \ldots \ldots \ldots$

ACKNOWLEDGEMENTS ......................... 19

REFERENCES. ............................. 20

\section{LIST OF ILLUSTRATIONS}

$\underline{\text { Figure }} \quad \underline{\text { Page }}$

1 Average $\Delta B(\gamma)$ from $O G O 2,4$, and 6 for $K p=2-$ to 3+, altitude $<550 \mathrm{~km}$, and northern hemisphere. (From Langel, 1974c) . . . . . . . . . . . . . . . . . . . . . . .

2 Conceptual drawing of proposed current sources (Langel, 1974b). The latitudinally broad current in the negative $\triangle B$ region, $11^{\mathrm{h}}$ to $18^{\mathrm{h}}$ MLT, is called the HLS current (High Latitude, Sunlit). Eastward and westward electrojets are shown as large arrows. These currents are assumed to flow in the ionospheric $E$ region and this figure is for the summer season. The positive $\Delta B$ region, shaded, is due to a nonionospheric source(s) in addition to the westward electrojet. Coordinates are invariant latitude and magnetic local time ...

3 The interplanetary magnetic field $\phi$ angle distributions for polar-cap electric fleld signatures. (From Heppner, 1972c) ..

4 Dlustration of correlation between $\Delta B$ and electric field patterns in the northern (summer) hemisphere. Boundaries and zero crossings are labeled with Roman numerals for the $\triangle B$ and Arabic numerals for the electric field. . . . . . . . . 
5 Example of $\triangle B$ pattern and simultaneous electric field pattern in the northern hemisphere .............

6 Examples of $\Delta \mathrm{B}$ and electric fleld patterns in the southern hemisphere. Coordinates are dipole latitude and magnetic local time. . . . . . . . . . . . . . . . . . .

7 Examples of $\backslash \mathrm{B}$ and electric field patterns in the southern hemisphere. Coordinates are dipole latitude and magnetic local time. . . . . . . . . . . . . . . . . . .

$8 \quad \triangle B$ and electric field patterns from selected quiet periods. Data are from the northern hemisphere and coordinates are dipole latitude and magnetic local time $\ldots \ldots \ldots \ldots \ldots \ldots$

9 Scatter diagram of Me vs. the peak magnitude of negative $\therefore B$ in the northern hemisphere...............

10 Qualitative sketch of a type of current flow consistent with multiple peaks in the negative $\backslash B$ region and with the associated electric field. 


\section{A COMPARISON OF ELECTRIC AND MAGNETIC FIELD}

\section{DATA FROM THE OGO-6 SPACECRAFT}

Magnetospheric and ionospheric currents causing magnetic field variations at high latitudes near the earth have principally been studied utilizing data from magnetometers at the earth's surface (see review by Rostoker, $1: 72$ ). In recent years the scope of investigation has been broadened by measurements of electris field (see review by Maynard, 1972), by satellite measurements of magnetic field disturbances caused by field aligned currents (Z muda et al., 1966, 1967; Armstrong and Zmuda, 1970, 1973; Theile and Praetorius, 1973), and by satellite mrasurement of disturbances in magnetic field magnitude (Dolginov et al., 1972; Langel, 1974a, 1974b). This paper utilizes simultaneous measurements of electric field (one horizontal axis only) and magnetic field (magnitude only) to further investigate the sources of disturbance in high latitude magnetic fields. The basic approach is to note the correlations in boundaries, amplitudes and other features between electric field patterns and magnetic disturbance patterns. These correlations are interpreted in terms of current locations and directions compatible w:th the measured electric and magnetic fields and in terms of source characteristics known from previous investigations.

The basic morphology of the variation or disturbance in total magnetic field at the POGO (OGO 2, 4, and 6) satellites, without regard to the interplanetary 
magnetic field sector, and the interpretation of that morphology in terms of sources have been previously presented by Langel (1974a, b, henceforth referred to as papers I and II). A description of the dependence of this disturbance on interplanetary magnetic sector structure is given by Langel (1974c). Only the total field is measured in these experiments, and the quantity analyzed is $\Delta B=$ $|\vec{B}|-|\vec{M}|$ where $\vec{B}^{\prime}(=B)$ is the quantity measured, and $\vec{M}$ is the corresponding field vector derived from a model of the quiet time field, represented by spherical harmonics (details are in paper I). The measurement accuracy, including orbital errors, is in general better than 6\%. Paper I describes the contours of average $\Delta \mathrm{B}$ as a function of season, $\mathrm{Kp}$, and altitude. Figure 1 illustrates the basic pattern of $\triangle B$, which is positive from about $22^{\mathrm{h}}$ to $10^{\mathrm{h}}$ MLT (magnetic local time) and negative from about $10^{\mathrm{h}}$ to $20^{\mathrm{h}}$ MLT. The standard error of the averages from which Figure 1 is derived are $\leq 10 \%$. This pattern is found at all seasons, Kp levels and altitudes, and its main features are two regions, denoted as the positive $\Delta \mathrm{B}$ region and the negative $\Delta \mathrm{B}$ region respectively. In paper II It was shown that in neither region can a latitudinally narrow electrojet current be considered as the principal source. Figure 2 summarizes the proposed source current distribution for summer months, omitting continuity in some regions where it is believed that field aligned currents may be important because conductivity gradients there are expected to exceed electric field gradients (see, e. g., Heppner, et al., 1971). A latitudinally broad current in the sunlit region between about $10^{\mathrm{h}}$ and $19^{\mathrm{h}}$ or $20^{\mathrm{h}}$ MLT produces both the negative $\triangle \mathrm{B}$ region 
and positive bays in the auroral belt. The latitudinally narrow westward electrojet from about $22^{\mathrm{h}}$ to $8^{\mathrm{h}}$ contributes some of the positive $\Delta \mathbf{B}$, particularly at low sltitude, but most of the positive $\Delta B$ is shown to be extra-ionospheric in origin. The latitudinally narrow eastward electrojet is only detected in low altitude passes between $18^{\text {h }}$ and $22^{\text {h }}$ MLT.

Variations in average $\Delta B$ between sectors are large in summer and small in winter. In summer, for example, in Figure 1 for away sectors the negative $\triangle B$ region extends to $8^{h}$ at $80^{\circ}$, while for toward sectors it extends only to about $11^{\text {h }}$. Near $7-8^{\mathrm{h}}$ above $80^{\circ}$ for away sectors $\Delta B$ is negative $(\leq-20 \gamma$ in summer), while for toward sectors $\Delta B$ is positive ( $\geq 20 \gamma$ in summer). The largest change ccclirs in the region between $80^{\circ}$ and $86^{\circ}$ and between $7-10^{\mathrm{h}}$, where the difference in average $\triangle B$ in summer reaches $100 \gamma$. At equinox the differences in average $\triangle B$ in this region are near $20 \gamma$, while in winter, differences between the two sectors from $6^{\mathrm{h}}$ to $18^{\mathrm{h}}$ are of the order of the standard errors of the averages. (Season, for the average data, is defined relative to the dipole latitude of the sub-solar point, $\theta_{\text {sun }}$, as follows: $\left|\theta_{\text {sun }}\right|<10^{\circ}$ is equinox, $\dot{c}_{\text {sun }}>10^{\circ}$ is (northern) summer, and $\theta_{\text {sun }}<-10^{\circ}$ is (northern) winter.)

It is now apparent that convective electric fields are always present over a large area of the polar regions (Heppner, 1972 a, b, c). Heppner (1972a) has succeeded in classifying the electric fleld distributions from OGO 6 data in terms of characteristic "signatures" in the polar-cap portion of the electric field pattern. Only passes crossing the noon-midnight meridian between $\Lambda$ (invariant 
latitude) $=75^{\circ}$ on the night side and $\mathrm{A}=85^{\circ}$ on the day side were so classified

in the northern hemisphere. In the southern hemisphere, passes crossing between $\Lambda=85^{\circ}$ on the day side and $\Lambda=85^{\circ}$ on the night side were similarly classified. Using this classification in terms of signatures, Heppner was able to show a high correlation between the occurrence of away interplanetary sectors and signatures with stronger fields on the morning (evening) side of the polar cap in the northern (southern) hemisphere. During towara sectors the polar cap electric field usually was constant or had a peak in the evening in the northern hemisphere and a peak in the morning in the southern hernisphere. These correlations are illustrated in Figure 3 (From Heppner, 1972c).

Because hoth the average $\Delta B$ patterns and the individual electric field patterns show variations between interplanetary magnetic field sectors, it is not surprising tilat currelation between the characteristics of simultaneous $\Delta B$ and electric field patterns is found in the OGO-6 Data. That such correlations exist was first pointed out to the author by Heppner (personal communication, 1974).

\section{SIGNATURE CORRELATION}

Simultaneous data of good quality are available for the period 10-20 June 1969. In correlating $\triangle B$ and electric field patterns, only passes which crossed the noon-midnight meridian at $A \geq 85^{\circ}$ and had well defined $\triangle B$ and electric field patterns were considered. The satellite was at low altitudes $(400-600 \mathrm{~km})$ in the northern (summer) hemisphere and at high altitudes $(800-1050 \mathrm{~km})$ in the soutl.ern (winter) hemisphere. 
Pattern correlations for the northera hemisphere are illustrated by a sequence of six idealized diagrams in F'igure 4. Polar cap electric field profiles include those peaked in the evening (Diagram A), relatively flat profiles (Diagram B), profiles with a tendency to peak near dawn (Diagrams C and D) and profiles having a tendency to peak near dawn with multiple crossing on the evening side of the polar cap (Diagram $F$ ). The $\triangle B$ patterns exhibit two types of variation letween pattern type. First, the zero crossing between the negative and positive $\Delta \mathrm{B}$ regions tends to move progressively from near the noon-midnight meridian toward the morning auroral belt as the patterns progress from Diagram A to Diagram $F$. Second, the negative $\Delta B$ region varies írom a smooth curve peaked near dusk (Diagrams A-C), to a broadly peaked region (Diagram D), to a flat region over a wide range of latitudes with a peak near dusk (Diagram E), and to a multiple peaked pattern (Diagram F).

Patterns with the cheracteristics shown in Diagrams A-B occir almost exclusively during toward interplanetary magnetic sectors while patterns with the characteristics shown in Diagrams D through F occur almost exclusively during away sectors. Most patterns like Diagram C occur during away sectors but some occur during toward sectors. This correlation is the same as those found previously for average $\triangle B$ (Langel, 1973c) and for individual electric field patterns (Heppner, 1972c).

Some of the zero crossings, peaks and boundaries are highly correlated between the two types of data. These features being correlated are labeled on 
Figure 4 with the convention that roman numerals are utilized for $\Delta B$ pattern features and arabic numerals are utilized for electric field pattern features. As far as possible, correlated features on the two pattern types are designated by the same numerical value. In particular:

a) The electric field zero crossing (4) from the polar cap to the evening auroral belt is well defined for patterns $\mathrm{A}, \mathrm{B}, \mathrm{C}$, and $\mathrm{D}$. When adequate data are available, and multiple electric field crossings do not occur. (4) is generally within about $1-3^{\circ}$ of the minimum, (IV), of $\Delta B$, and within $1-2^{\circ}$ when (4) is a sharp peak.

b) For some of the very broad negative $\triangle B$ patterns $D$, and for patterns like $E$, the crossing (4) occurs near the center of the negative $\triangle B$ region, even If (IV) is not at the center of tine region.

c) For multiple humped negative $\Delta B$ patterns, like pattern $E$ or $F$, the crossing (4) occurs between the two minime of $\Delta \mathrm{B}$. If the electric field has multiple crossings, the equatorward (4) crossing is at or just poleward of the equatorward $\Delta \mathrm{B}$ minimum and the other electric field zero crossings lie between the two $\triangle B$ minima. Sometimes the poleward electric field zero crossing is very near the poleward $\triangle B$ minimum, and, in the purest examples of Pattern $F$, the central zero crossing occurs within $1-2^{\circ}$ of the maximum between the two negative $\triangle B$ minima.

d) For patterns $C, D, E$, and $F$ the electric field maximum near dawn, (7), almost always occurs poleward of the positive $\triangle B$ peak, generally about $2-5^{\circ}$ poleward, and to the dawn side of the $\Delta \mathrm{B}$ zero crossing, (VII). 
e) When it is well defined, the electric field peak, (2), in the morning auroral belt occurs between the $\Delta B$ peak, (III), and zero crossing (II), i.e. on the slope between (III) and (II). Structure in this portion of the electric field usually corresponds to structure in the $\triangle \mathrm{B}$ cl. re. For example, on Figure 5 near $9^{\text {h }} 12$ min two electric field peaks occur and an inflection occurs in $\Delta B$ such that each peak in electric field occurs in a portion of $\triangle B$ with a distinct slope. (Figure 5 also serves as an example of a pattern with features like diagrams $\mathrm{E}$ and $\mathrm{F}$ of Figure 4.) Cases can also be found of electric field structure in this region with no apparent corresponding $\Delta \mathrm{B}$ structure.

f) The electric field zero crossing, (3), and the positivi $\triangle B$ peak, (III), often occur within $1-2^{\circ}$ of each other, with some tendency for (III) to be poleward of (3).

g) The electric field peak, i5), generally occurs on the $\Delta B$ slope between (IV) and (V).

Southern hemisphere pattern correlations are not as obvious as those for the northorn hemisphere. The situation is complicated by the occurrence of large fluctuations in the electric fleld data. Two representative passes are shown in Figure 6. As expected for high altitude ( $800 \mathrm{~km}$.) winter hemisphere data (see papers I and II), the negative $\Delta B$ region is non existent or of negligible amplitude for all southern passes in this time period. The major differences in the two $\triangle B$ patterns in Figure 6 are that in Figure $6 \mathrm{~b}$ the peak, (II), of the $\Delta B$ is more rounded (i.e. broader) and is also more poleward than the peak in 
Figure 6a. Because the poleward shift of the peak, (III), in Figure $6 \mathrm{~b}$ is greater than the accompanying poleward shift of the zero crossing (II), the morning and evening side slopes of the $\Delta B$ curve are more ne arly equal in Figure $6 b$ than in Figure 6a. In most of the southern hemisphere passes with well defined $A B$ patterns the patterns are either like those in Figure 6 or have characteristics between these two extremes.

The polar cap electric field pattern in Figure $6 a$ is relatively flat, although there is a peak on the evening side and a large peak on the morning side. A somewhat unusual feature of Figure $6 \mathrm{~b}$ is that the auroral belt electric field on the dawr side extends to the pole. The polar cap electric field pattern in Figure $6 \mathrm{~b}$ is peaked in the evening. In Figure $6 \mathrm{~b}$ the polar cap electric field (i.e. the section of positive electric field) shows a tendency to be divided into two sections. The poleward section is of lower magnitude and has smaller fluctuations. At about $79^{\circ} \mathrm{a}$ jump in magnitude occurs and this equatorward segment, on the evening side, has a large number of high amplitude fluctuatioids together with a tendency for a broad peak in the pattern one would get if a smooth curve were rum through the fluctuations. This double amplitude type structure occurs on several passes.

Although the correlations are not as definite as in the northern hemisphere, IB patterns similar to Figure $6 a$ tend to be associated with relatively flat electric field patterns with a tendency to peak in the morning, and with electric field patterns with a definite peak in the morning. IB prtterns similar to Figure $6 b$ 
tend to be associated with polar cap electric field patterns peaked in the evening. Whth respect to interplanetary magnetic sectors, patterns like Figure 6a tend to occur during toward sectors and patterns like Figure $6 \mathrm{~b}$ tend to occur during away sectors. The porcentage of exceptions to these trends is significantly higher In the southern hemisphere than the percentage of exceptions to the correlations discussed for the northern hemisphere data.

Figure 7 illustrates another type of ..B pattern which occurs in the southern hemipshere. In these cases the magnitude of the positive $\mathrm{AB}$ remains high over a larger portion of the orbit, resulting in patterns with more of a "flat" type distribution than seen in Figure 6. This type of pattern is relatively rare in the time period under consideration but is common in some other ime periods. Because of the sparcity of cases, it is not possible to establish a good correlation with either the electric field patterns or with interplanetary magnetic sectors. Both polar cap electric field patterns shown are relatively flat; the interplanetary field is away for Figure 7a and toward for Figure $7 \mathrm{~b}$.

Sorthern hemisphere correlations between peaks and zero crossings are as follows (see, e. g., Figure 6):

a) As in t:e northern hemisphere, the electric field peak, (2), in the morning proral belt occurs between the IB peak, (III), and zero crossing, (II), l.e. on the slope betwee: (II) and (II). Unlike the northern hemisphere, structure in this portion of the electric field is not found to correspond to structure in the : IB curve. 
b) In most cases the electric field crossing (3) is not well defined because large fuctuations result in multiple crossings. When defined single crossings do occur, (3) is usually within $2^{\circ}$ of the $\triangle B$ peak (II). When the $\triangle B$ pattern is of the type Illustrated in Figure 6a, the multiple electric field zero crossings occur buth equatorward and poleward of the $\Delta B$ peak (III). When the $I B$ pattern is of the type illustrated in Figure $6 b$, the multiple electric field zero crossings tend to occur poleward of (III).

c) The evening auroral belt segment of the electric fleld is always equatorward of the main portion of positive. $\mathrm{B}$. When the .JB zero crossing (VII) is well defined, as in Figure 6a, the auroral portion of the electric field is equatorwand of (VII).

In addition to the patterns shown in Figures 4-7 are some patterns observed only during very quilet magnetospheric conditions. In the northern hemisphere, quiet time patterns sometimes have the form shown in Figure 8. Both the JB and the electric field are of low magnitude and both have a sinusoidal app arance. Because of uncertainties in both the magnetic field data and in the spherical harmonic model used to compute $\triangle B$, the $\triangle B$ zero level is uncertain to about 5-10y. The nature of the $\Delta B, 1, e$, its sinusoidal character and the locations of the $\triangle B$ peaks, does not change signiflcantly between field models, but the locations of the zero crossings of $\mathrm{AB}$ are uncertain. Comparison of Figure 8 with pattern F of Figure 4 (note that posilive values are up on Figure 4 but down on Figure 8) indicates that the patterns of Figure 8 may be an extreme form of pattern $F$ of 
Figure 4. Examination of Figure 8 shows a tendency for zero crossings of the electric fielu to occur at or near peak values of .U. Perhaps the most puzzling feature is the continuation of the sinusoidal .IB variations to lower latitudes than the electric field osrillations in Figure $8 b$. In the absence of.this feature it would be posstble to account for the . B pattern in terms of Hall currents in the directions implied by the electric field.

Heppner (1973) has noted a tendency for weak electric fields in the northern hemisphere to occur on the same orbit as highly irregular electric fields in the southern hemisphere. These are, of course, also very quiet periods in terms of magnetic activity. The soutiern . B during these passes shows very little variation but often has a positive value between $5-15$, Tr $:$ reason for this positive IR is uncertain. Possibilities include: 1) a field due to a lithospheric magnetic anomaly not completely described by the field models used, 2) incomplete representation of fields from the equatorial current shet by the field models used, 3) inadequate knowledge of the spacecraft orbit, or t) fields from an ionospheric scurce. Because of the highly irregular nature of the electric fields, possibulity 4) seems unlikely. The other possibllities are under investigation.

\section{AMPLITUIF, CORRELATIONS}

Amplitude correlations are difficult to make in a clearly meaningful way. It is possible to compare elther the peak of the electric field or the potential drop over the polar cap with . IB. Examination of the individual passes indicates 
n general tendency for large values of $\lrcorner$ B to be associated with higher values of electric field.

The following procedure has been followed to make a semi-quantitative :omparison of $\mathrm{AB}$ and electric field amplitudes:

1) an "average" magnitude for the polar cap electric field is estimated.

2) The satellite path length, in units of $10^{\circ}$ dipole latitude, is estimated for that portion of the pass when polar cap type electric fields are present.

3) The product of the above two quantities, called Me, is used to estimate the "strength" of the potential drop.

1) Me is then plotted versus the peak value of positive and negative . $B$. The results for northern hemispiere negatives i 13 are given in Figure 9. Because of the uncertainty in finding the average value of electric field, widely rarying type if electric field patterns were initially plotted with different symbols. However, no significant differences were noticeable so this practice vins discontinued. A definite trend of increasing ..B with increasing Me is scen in Figure 9, but the scatter is large.

A simila bat weaker, trend is found for positive $\backslash B$ in the northern hemisphere th the southern hemisphere positive. IB shows no definite trend as a fu stion of Me. Correlation coefficients between . VB and Me are $0.58,0.49$, and 0.36 for the northern hemisphere negative $.1 B$, the northern hemisphere positive $B$, and the southern hemisphere positive. iB respectively. The scatter 
In the positive AB vs. Me comparison is not solely due to uncertainties in estimating Me. This is shown by the existence of passes on which the electric field Is fairly simular both In pattern and magnitude, yet on whloh the positive $\lrcorner B$ differs by as much as a factor of two.

\section{DISCUSS")N}

Langel (paper I and In) concluded that all of the negative $J B$ is due to a latitudinally broad ionospheric $\mathbf{E}$ region current with little, if any, contribution from latitudinally narrow jet-type currents. The positive IB was attributed to both a westward electrojet and to a non-ionospheric source of positive. $\mathrm{B}$. At altitudes less than $550 \mathrm{~km}$ these two sources were, on the average, thought to contribute nearly equally to the positive .lB.

Consider first the negative $\mathrm{AB}$ region. If the source of. $\mathrm{AB}$ were a jet-type current in the auroral belt, the maximum current would flow in the region of auroral beit electric field, i.e. near peak (5) in Figure 4, and . $\backslash$ B would show a negative peak poleward and a positive peak equatorward of this current. For this case one would expect the IB zero crossing, (V), to he well defined and located near the electric field peak, (5). On the other hand, for a broad current of the $S_{q}^{p}$ type, one would expect a large negative . IB near the current vortex. Further, the current vortex would be located at the zero crossing, (4), of the electric field. The strong currelation observed between the electric field zero crossing, (4), anci the penk negative $A B$, (IV), strongly supports this second interpretation. 
Langel (1973) and Langel and Brown (1974) noted two distinct negative peaks In the averaged $I Z$ at the earth's surface during away sectors for summer. Since $J B: J Z$ at these latitudes, it is appropriate to look for this feature in the satellite iB. Such a feature is not apparent in the averaged IB (Langel, 1974c). However, the existence of field patterns such as $F$, and to a certain extent $E$, of Figure $t$ and Figure 5 shows that such a leature can be present in the $.1 \mathrm{~B}$ data, and that it is associated with structure in the electric field pattern, as would be expected if the source was an ionospheric current. From the averaged surface $\because Z$ it was not possible to tell if the two negative $Z Z$ peaks are a permanent feature during away sectors. From the present data it can be seen that this is not a permanent feature but depends upon the electric field configuration. It seems probable that the patterns of Figure 4 may be regarded as a logical sequence corresponding to the way the masnetospheric plasma flow changes in response to interplanetary conditions. The sequence of conditions is only partially known, (1. e., the response to the azimuthal component of interplanetary fleld).

As already noted, Figure 4 is an idenlization; much moro variety/variability is present in the original data. Clearly, it is not menningful to draw equivalent clirrent patterns to represent the observed data in any detailed fashion. The general features of the electric field and IB patterns do, however, support the notion of a broad $s_{4}^{\prime \prime}$ - like current in the $11-18^{\prime \prime}$ MLT region, as illustrated in Figure 2, with large-variability with time. For example, the variant correspondIng to pattern E of Figure 4 might be like the current sketched in Figure 10. 
In the positive $\triangle B$ region the relation between the electric field peak and zero orossing, (2) and (3), and the $\triangle \mathrm{B}$ peak, (III), is similar to the relation between the electric fleld peak and zero crossing, (5) and (4), and the $\Delta B$ peak, (IV), in the negative $\triangle B$ region. In contrast to the negative $\triangle B$ region, a significant number of cases exist for the positive $1 \mathrm{~B}$ region where a substantial negative $\mathrm{IB}$ is present equatorward oi the auroral belt zero crossing of .1B. This configuration is exactly what is expected from the combination of the westward electrojet with a nonlonospheric source. The vertical field disturbance from the non-lonospheric source reduces the magnitude of the equatorward $J B$ and shifts the JP zero crossIng equatorward. At times when the westward jet beneath the satellite is weak or absent and at high altitudes where the electrojet field is weak, the equatorward negative $\Delta B$ is small or absent.

It is of course not possible to verify the existence of a non-ionospheric positive $\Delta B$ from the northern hemisphere data alone. The electric field and IB patterns would also permit interpretation of the positive $\lrcorner \mathrm{B}$ region in terms of a latitudinally broad ionospheric current together with a westward electrojet. The exdstence of the non-ionospheric positive IB was inferred in paper II from the altitude variation of the positive $\Delta B$. In particular, for a fixed Kp ringe, the average $|\Delta B|$ decreases less than a factor of two between 450 and $1000 \mathrm{~km}$ in the positive $\Delta B$ region, whereas the decrease is generally greatis than \& fictor of ten in the negative $\Delta B$ region. This altitude variation may be s9en in a semiquantitative way in the present data. The magnitude of negativo ist at low altitudes 
In the summer is comparable to the magnitude of the positive $\Delta \mathrm{B}$, whereas at high altitudes in the winter the negative $\Delta \mathrm{B}$ is negligible. On the other hand, the positive $\triangle B$ at high altitudes in the winter is roughly half the magnitude of the positive. $\mathrm{B}$ at low altitudes in the summer.

The prescnca of some correlation in pattern features between the morning auroral belt electric field and the positive $\triangle B$ for the low altitude data is indicative of at least a partial ionospheric source. On the other hand, lack of detailed correlation is evidence that a non-ionospheric source also exists. The existence of cases where the negailve $J B$ equatorward of the auroral belt zero crossing of $\Delta B$ is within a factor of 3 in magnit: ${ }^{n}$ of the positive $\Delta B$ peak indicates that at least a portion of the lonospheric clivent is at times latitudinally narrow, or jet-like. However, the absence of this equatorwaru negative $J B$ cannot be taken to indicate the absence of a jet-type current, because it is possible for a nonionospheric positive $\mathrm{AB}$ to pe large enough to completely obscure the negative \lrcorner $B$ in this region.

Consideration of the correlation coefficients between $M_{e}$ and the peak $\triangle B_{i}$ also supports the proposed source distribution of Figure 2. The region of $\Delta B$ attributed mainly to ionospheric current, namely the northern hemisphere negative A B region, has the highest correlation coefficient, 0.58 . The lowest correlation coefficient, 0.36 , is obtained for the southern, higher altitude, positive $\ B$ region which is the region thought to be dominated by a non-lonospheric source. Lying between these two regions is the low altitude northern positive $\triangle B$ region with a 
correlation coefficient of 0.49 . This is the region where $\Delta B$ is thought to be due to both ionospheric and non-ionospheric sources, in about the same proportion.

It has been shown that the $\Delta \mathrm{B}$ magnitude and electric fleld magnitude are not significantly ccmelated in the southern (winter, altitude $>800 \mathrm{~km}$ ) data and that no corresponience between electric field fluctuations and $\Delta B$ fluctuations is found in the south, in contrast to cases like Figures 5 and 8 in the northern data. Yet the overall correlation between the dawn boundaries of the. $\mathrm{B}$ and electric field patterns is as strong in the south as it is in the north. Examination of individual passes from both hemispheres shows that this correlation occurs even when latitude shifts of $5-12^{\circ}$ in these boundarles occur for passes at similar UT. This correlation implies that a portion of the non-ionospheric source of positive $\triangle B$ may be located at or near the equatorward convection boundary. Langel (paper II; 1974d) has already considered that the equatorial current sheet (ECS, or ring current) may be a source of high latitude positive $\Delta B$. Examples were given in paper II of individual passes where reasonable estimates of combinations of disturbance from the ECS and electrojet sources were not consistent with the measured positive $\triangle B$. Also, a comparison of nearly simultaneous data from COSMOS-321 at aboui $200 \mathrm{~km}$ and OGO-6 at about $800 \mathrm{~km}$ indicates that the positive $\triangle B$ is not caused by ionospheric currents together with the ECS unless the induced currents associated with the ECS are much smaller than is indicated by low latitude data (Langel, 1974d). From the present study there are two features of the high altitude data from the southern hemisphere which seem 
inconsistent with the ECS as the major source. The disturbance due to the ECS is expected to cause a disturbance aligned according to the dipole axis. Changes in the ECS might result in magnitude changes in a $\triangle B$ pattern but should not result in the $5-12^{\circ}$ latitude shifts that have been noted to correlate with the electric fleld peak (2). Also, a symmetric magnetospheric disturbance aligned according to the dipole axis should have its peak at or near the dipole pole. When assymetry exists in the ECS, the disturbance magnitude is greater in the evening than in the morning. The positive $\triangle B$ peak, however, usually occurs at least $7-10^{\circ}$ equatorward of that pole on the morning side.

Because a non-ionospheric source is required for high latitude positive $\Delta B$, and because the ECS does not seem capable of causing the measured disturbance, another source is required. Such a source must be consistent with the correlation between $E$-field and $\triangle B$ pattern boundaries. When discussing deficiencies in the ability of a model magnetospheric current system, Sugiura and Poros (1973) noted that to date such models do not include current flow in the dayside cusp. Also not included is the possibility of current flow in the high latitude "horns" of the nightside plasma sheet. Sugiura (1974) has recently shown how the magnetic field in these regions is topologically connected. It seems possible that some sort of current at relatively low altitude ( $\geq 1000 \mathrm{~km}$, say) in this region could be the source of high latitude $\Delta B$. 


\section{ACKNOWLEDGEMENTS}

I am Indebted to J. P. Heppner for the use of the OGO-6 electric field date

and to N. C. Maynard, J. P. Heppner, and D. P. Stern for valuable critical

discussion. 


\section{REFERENCES}

Armstrong, J. C., and A. J. Zmuda, Field-aligned current at $1100 \mathrm{~km}$ in the auroral region measured by satellite, J. Geophys. Res., 75, 7122, 1970.

Armstrong, J. C., and A. J. Zmuda, Triaxial magnetic measurements of fieldaligned currents at $800 \mathrm{~km}$ in the auroral region: Initial results, J. Geophys. Res., 78, 6802, 1973.

Dolginov, Sh. Sh., L. N. Zhigalov, L. V. Strunnikova, Ya. I. Feldshteyn, T. N. Cherevko, and V. A. Sharova, Magnetic Storm of March 8-10, 1970, according to ground based and Kosmos-321 observations, Geomagn. i. aeronomiya, 12, Engl. trans., 909-918, 1972.

Heppner, J. P., Electric field variations during substorms; OGO 6 measurements, Planet. Space Scl., 20, 1475-1498, 1972.

Heppner, J. P., Electric fields in the magnetosphere. Critical Problems of Magnetospheric Physics, proceedings of a Joint COSPAR/IAGA/URSI Symposium, Madrid, Spain, 11-13 May 1972 (ed. E. R. Dyer), p. 107 IUCSTP Secretariat, c/o National Academy of Sciences, Washington, D. C., U.S.A., 1972b.

Heppner, J. P., Polar cap electric field distributions related to the interplanetary magnetic fleld direction, J. Geophys. Res., 77, 4877, 1972c.

Heppner, J. P., High latitude electric fields and the modulations related to interplanetary magnetic field parameters, Radio Sclence, $\underline{8}, 933,1973$. 
Heppner, J. P., J. D. Stolarik, and E. M. Wescott, F.lectric field measurements and the identification of currents causing magnetic disturbances in the polar cap, J. Geophys. Res., 76, 6028, 1971.

Langel, R. A., Average high latitude magnetic field: Variation with interplanetary sector and with season; I. Disturbed conditions, Planet. Space Sci., 21, 839, 1973.

Langel, R. ^ ., Near earth magnetic disturbance in total field at high latitudes; I. Summary of data from OGO's 2,4 and 6 , J. Geophys. Re $, \underline{79}, 2363,197 \pm$ ia.

Langel, R. A., Near earth magnetic disturbance in total field at high latitudes;

II. Interpretation of data from OGO's 2,4 , and 6, J Geophys. Res., $\underline{79}$, $2373,1974 b$.

Langel, R. A., Variation with interplanetary sector of the total magnetic field $\mathrm{m}$ sasured at the OGO2, 4, and 6 satellites, Planet. Space Sci., in Press, 1 s74c.

Langel, R. A., A Comparison of High latitude magnetic field data from OGO-6

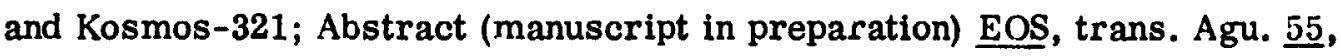
$403,1974 d$.

Langel, R. A. and N. Brown, Average High Latitude magnetic field: Variations with interplanetary sector and with season, $\Pi$. Comparison of disturbance levels and discussion of ionospheric currents, accepted for publication in Planet. Space Sci, , 1974.

Maynard, N. C., Elactric fields in the lonosphere and magnetosphere, in Magnetosnhere Ionosphere interactions, ed. K. Folkestad, Universitetsforlaget, Oslo, 1972. 
Rostoker, G., Polar magnetic substornis, Rev. Geophys. Space Phys., 10, $157-211,1972$.

Sugiura, M., Identification of the Polar Cap Boundary and the Auroral Belt in the High-Altitude Magnetosphere: A model for field-aligned currents, Report $\underline{X-625-74-195}$, Goddard Space Flight Center, June 1974.

Sugiura, M. and D. J. Poros, A magnetospheric field model incorporating the OGO 3 ad 5 magnetic field observations, Planet. Space Sci., 21, 1763-1773, 1973.

Theile, B., and H. M. Praetorius, Field aligned currents between 400 and $3000 \mathrm{~km}$ in auroral and polar latitudes, Planet. Space Sci., 21, 173, 1971.

Zmuda, A. J., F. T. Heurirg, and J. H. Martin, Transverse magnetic disturbance at 1100 idilometers in the aurural region, J. Geophys. Res., 71, 5033-5045, 1966.

Zmuda, A. J., F. T. Heuring, and J. H. Martin, Day side magnetic disturbances at 1100 kilometers in the auroral oval, J. Geophys. Res., 72., 1115-1117, 1967. 


\section{CAPTIONS}

Figure 1. Average : i ( 1 ) from OGO 2, 4, and 6 for Kp $=2-$ to $3+$, altitude $<550 \mathrm{~km}$, and northern hemisphere. (Fro:n Langel, 1974c).

Figure 2. Concoptual drawing of proposed current sources (Langel, 1974b). The latitudinally broad current in the negative . IB region, $11^{\text {h }}$ to $18^{\text {h }} \mathrm{MLT}$, is called the HLS current (High Latitude, Sunlit). Eastward and westward electrojets are shown as large arrows. These currents are assumed to flow in the lonospheric E region and this figure is for the summer season. The positive 1 B rogion, shaded, is due to a non-ionospheric source(s) in addition to the westward electrojet. Coordinates are invariant latitude and magnetic local time.

Figure 3. The interplanotary magnetic field s angle distributions for polar-cap electric field signatures. (From Heppner, 1972c).

Figure 4. Illustration of correlation between $.1 \mathrm{~B}$ and electric field patterns in the northern (summer) hemisphere. Boundarios and zero crossings are labeled with Koman numerals for the $\mathrm{iB}$ and Arabic numerals for the electric fleld.

Figure 5. Example of $\backslash$ B pattern and simultaneous electric field pattern in the northern homisphere.

Figure 6. Examples of . IB and electric field patterns in the southern hemisphere. Coordinates are dipolo latitude and magnetic local time. 
Figure 7. Examples of $\mathrm{J} B$ and electric field patterns in the southern hemisphere. Coordinates are dipole latitude and magnetic local time.

Figure 8. $\mathrm{SB}$ and electric field patterns from selected quiet periods. Data are from the northern hemisphere and coordinates are dipole latitude and magnetic local time.

Figure 9. Scatter diagram of Me vs. the peak magnitude of negative $\lrcorner B$ in the northern hemisphere.

Figure 10. Qualitative sketch of a type of current flow consistent with multiple peaks in the negative .JB region and with the associated electric field. 


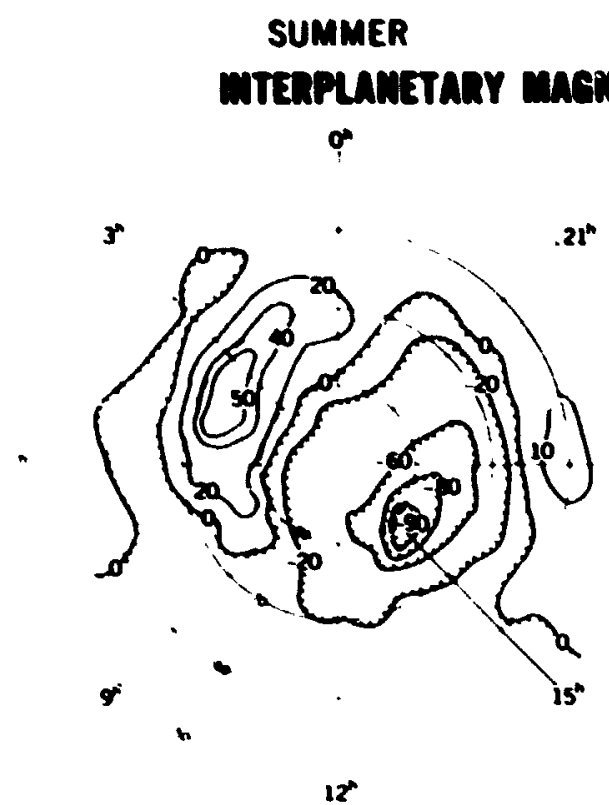

(A)
WINTER

FELL AWAY FROM THE SUN

ơ.

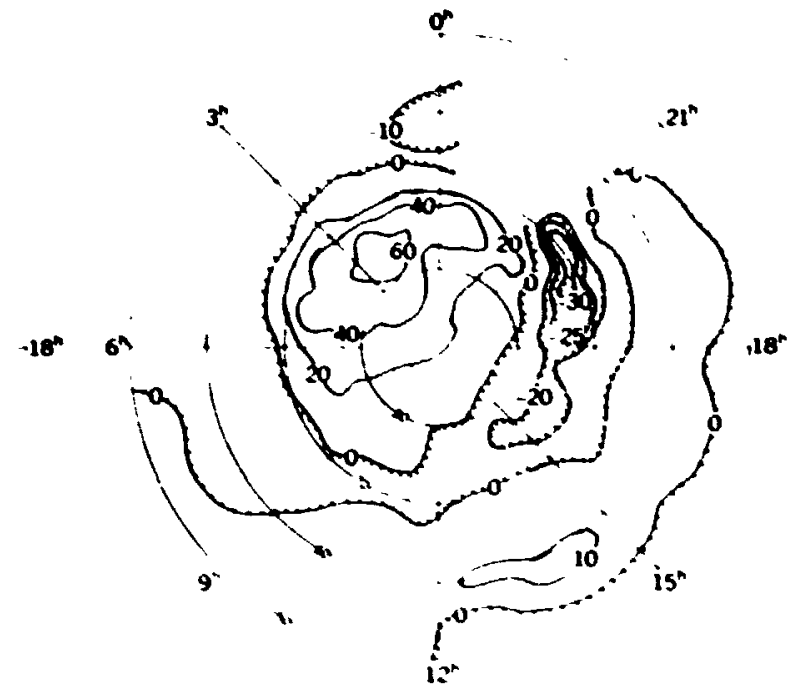

(B)

\section{IMTERPLANETARY mAGNETIC FIELD TOWARO THE SUN}

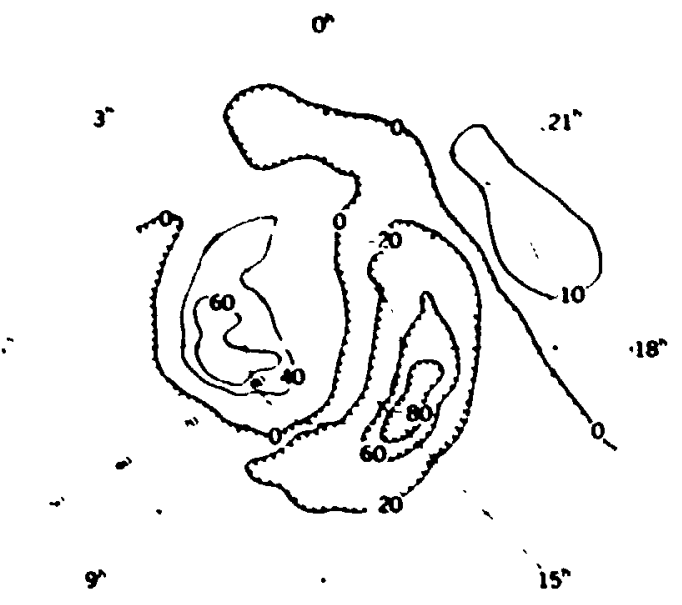

$12^{n}$

(C)

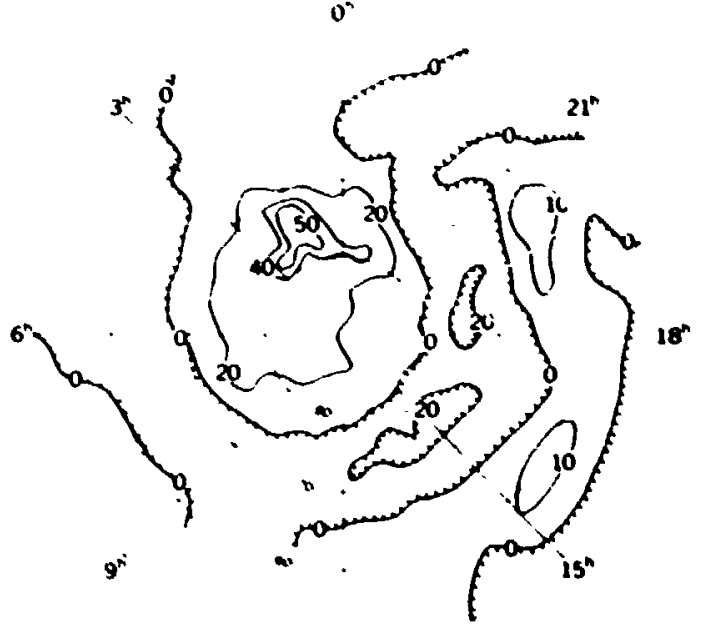

$12^{n}$

(D)

Figure 1. Average $\lrcorner B(\mathrm{~B})$ from $\mathrm{OGO} 2,4$, and 6 for $\mathrm{Kp}=2-$ to $3 t$, altitude < $550 \mathrm{~km}$, and northern hemisphere. (Fron Langel, 1974c). 


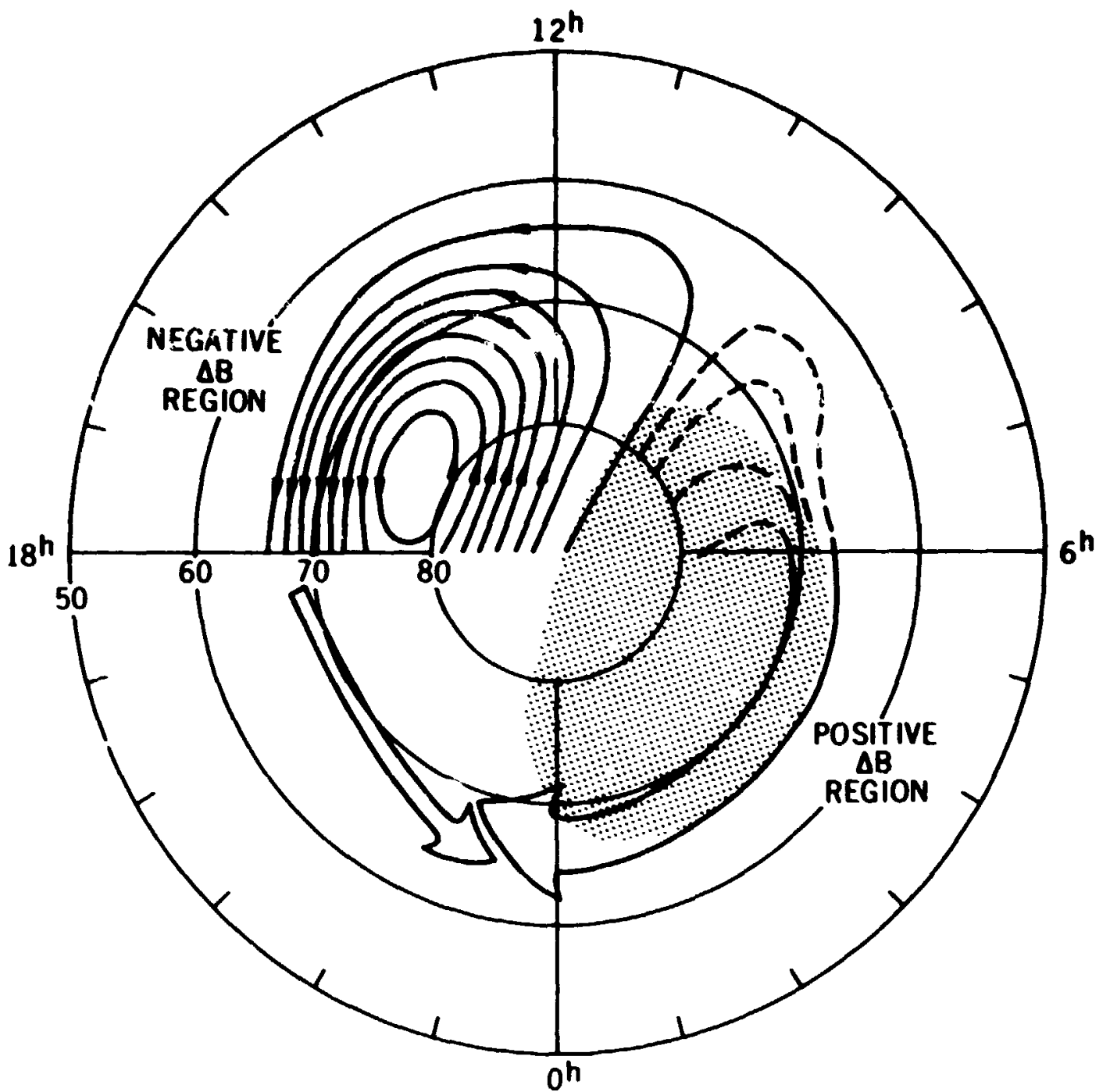

Figure 2. Conceptual drawing of proposed current sources (Langel, 1974b).

The latitudinally broad current in the negative. $\mathrm{B}$ region, $11^{\text {h }}$ to $18^{\mathrm{h}} \mathrm{MLT}$, is called the HLS current (High Latitude, Sunlit). Eastward and westward electrojets are shown as large arrows. These currents are assumed to flow in the ionospheric $\mathrm{E}$ region and this figure is for the summer season. The positive $J B$ region, shaded, is due to a non-ionospheric source(s) in addition to the westward electrojet. Coordinates are invariant latitude and magnetic local time. 


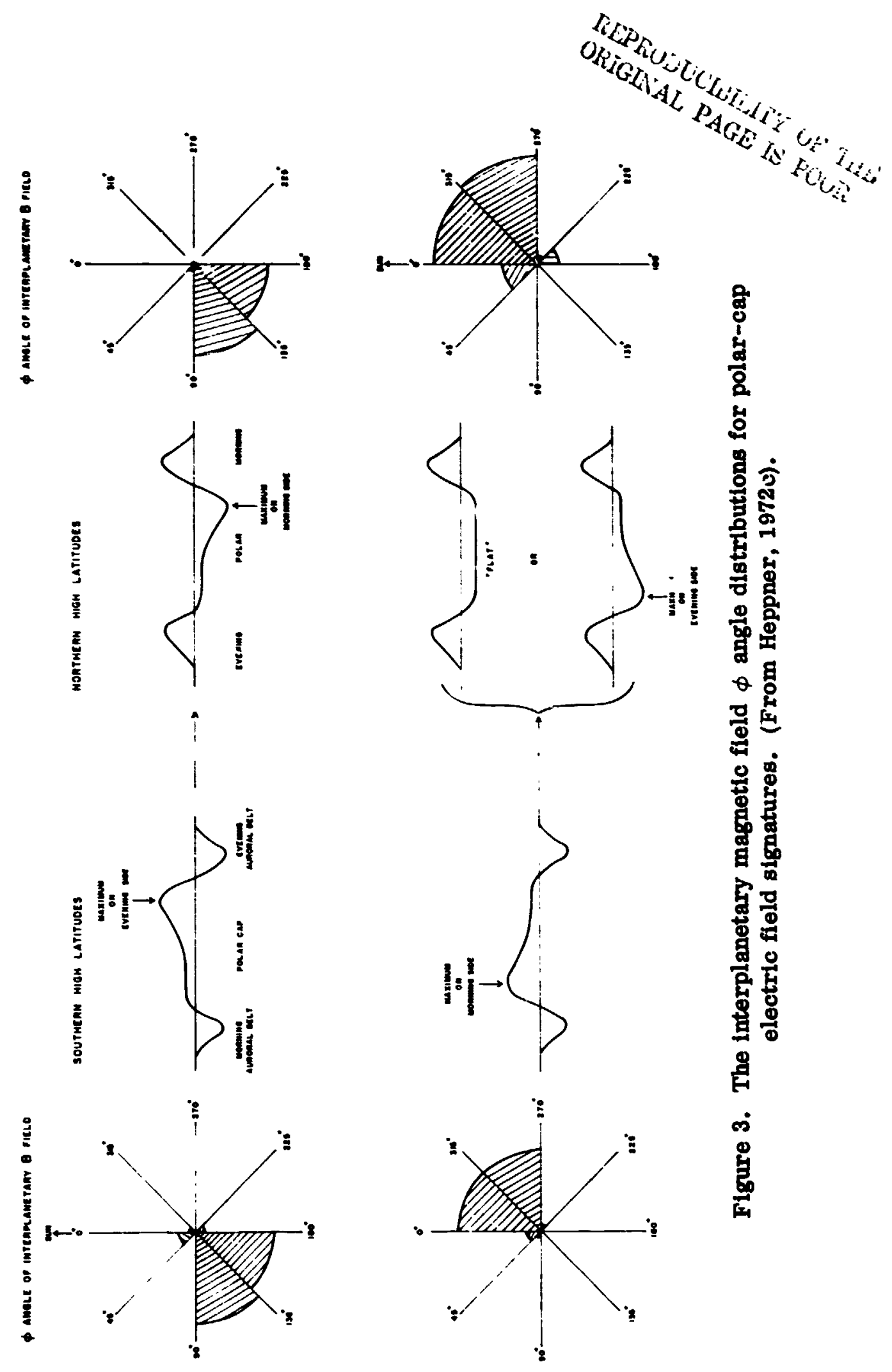




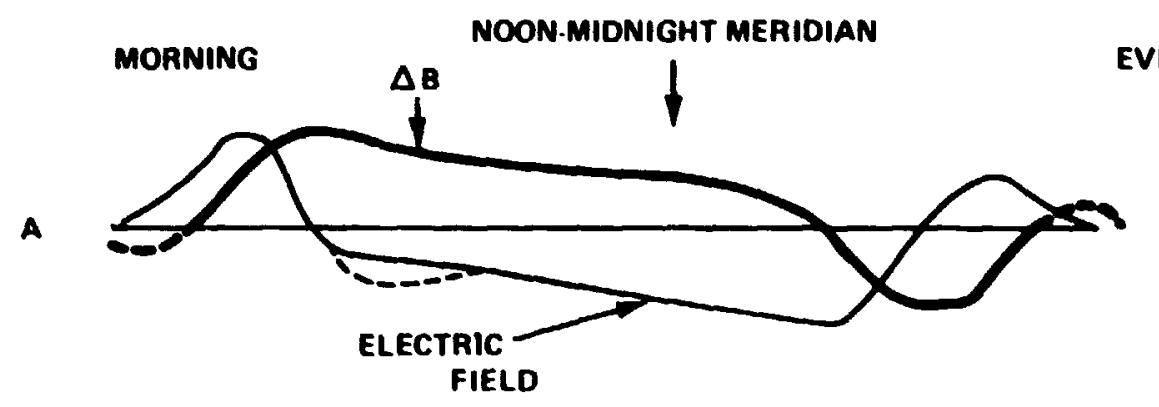

EVENING
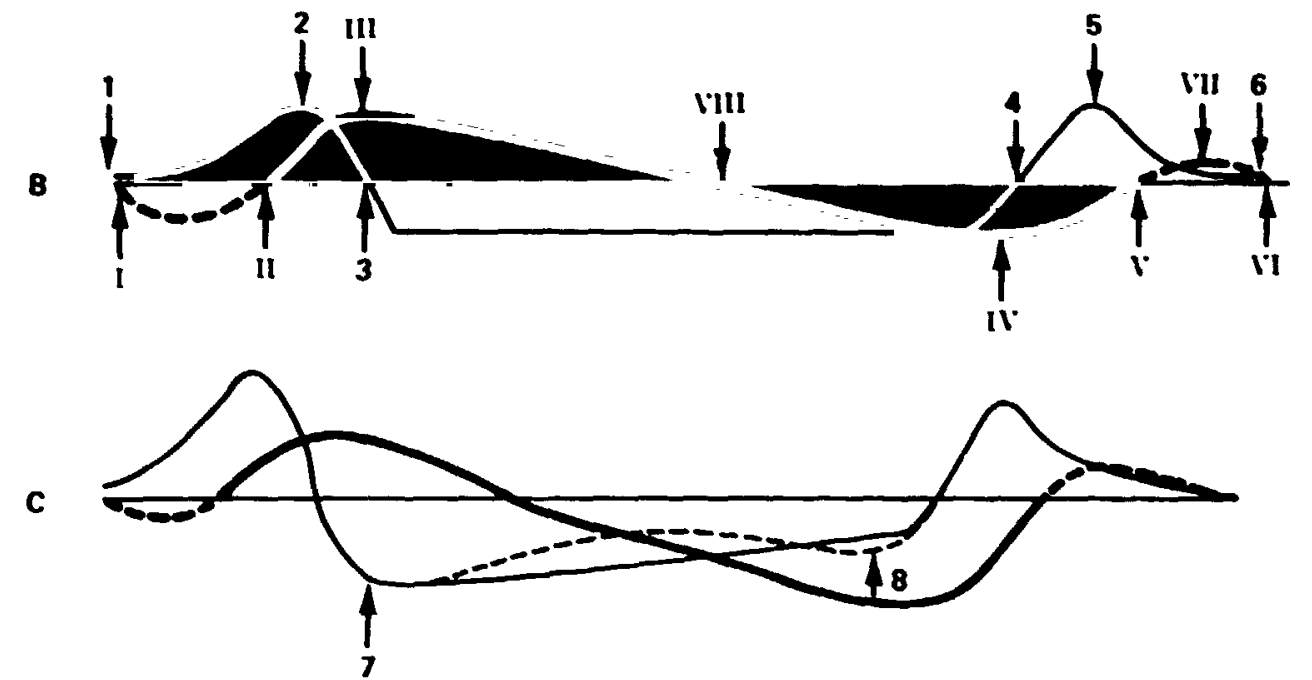

D
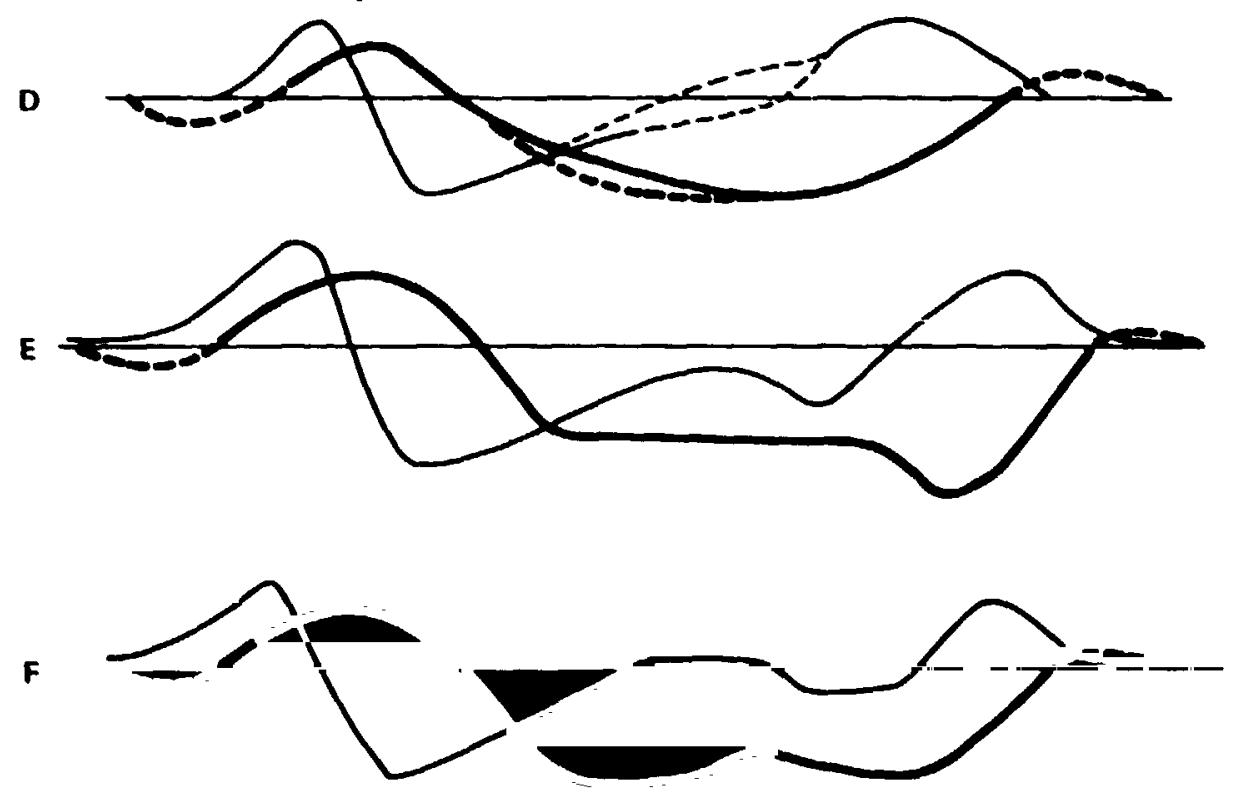

Figure 4. Illustration of correlation between . $\backslash \mathrm{B}$ and electric field patterns in the northern (summer) hemisphere. Boundaries and zero crossings are labeled with inoman numerals for the $\backslash \mathrm{B}$ and Arabic numbers for the electric field. 


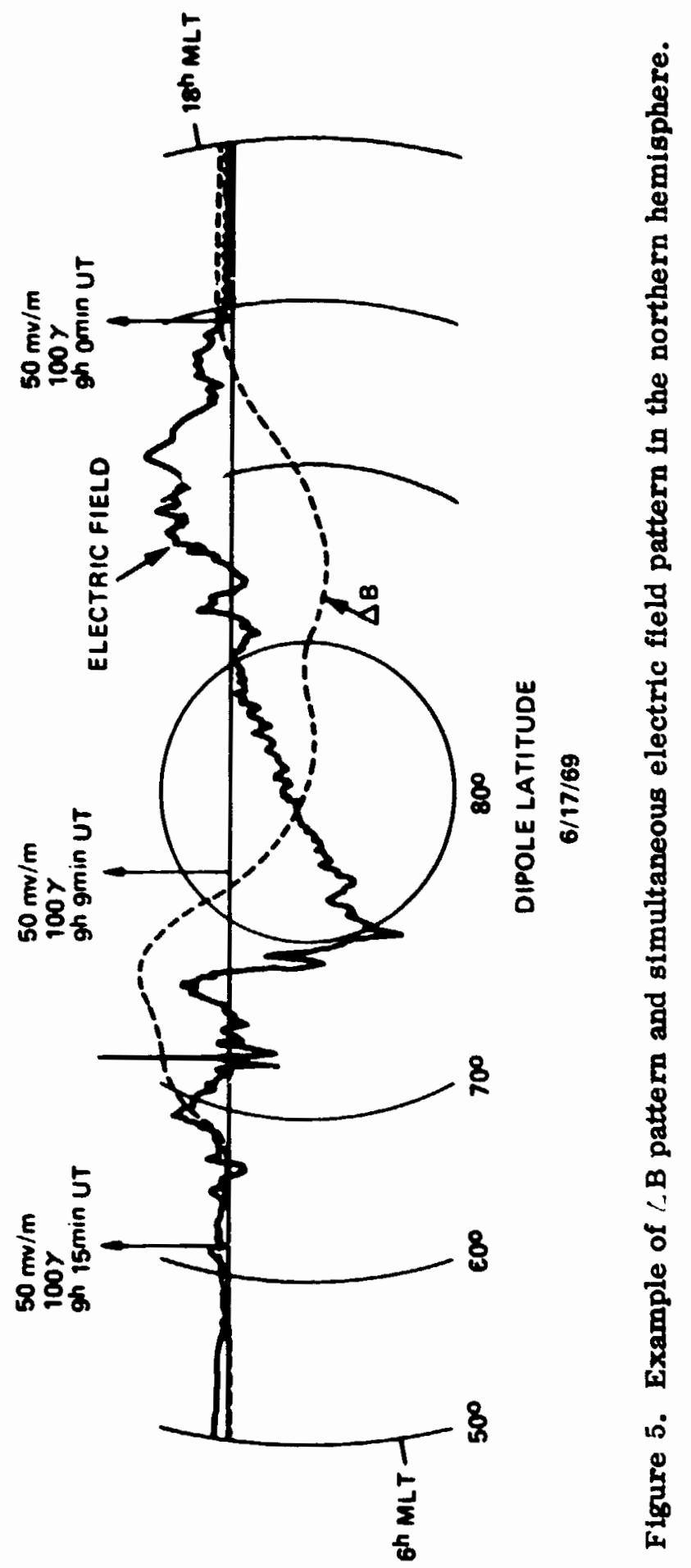



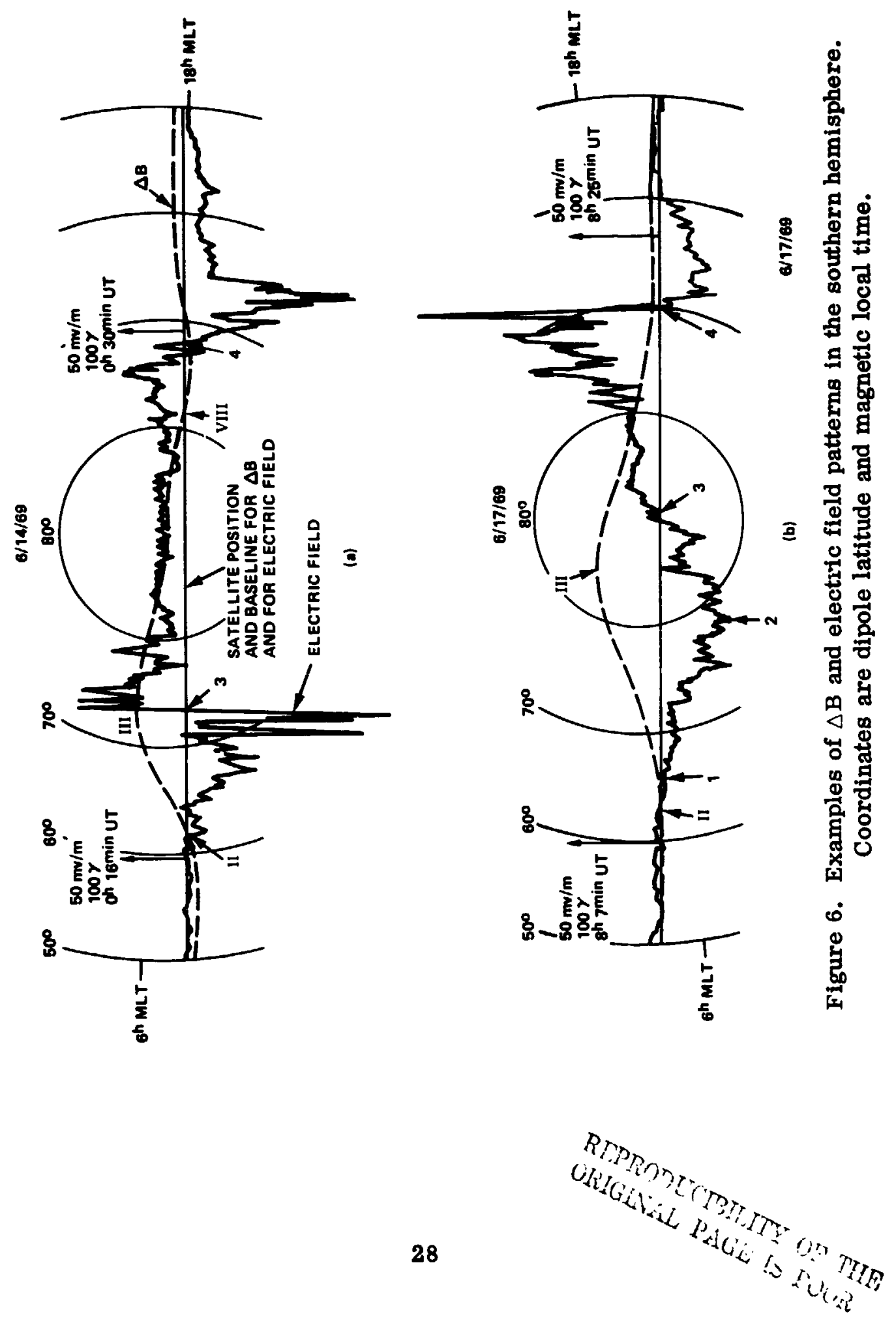

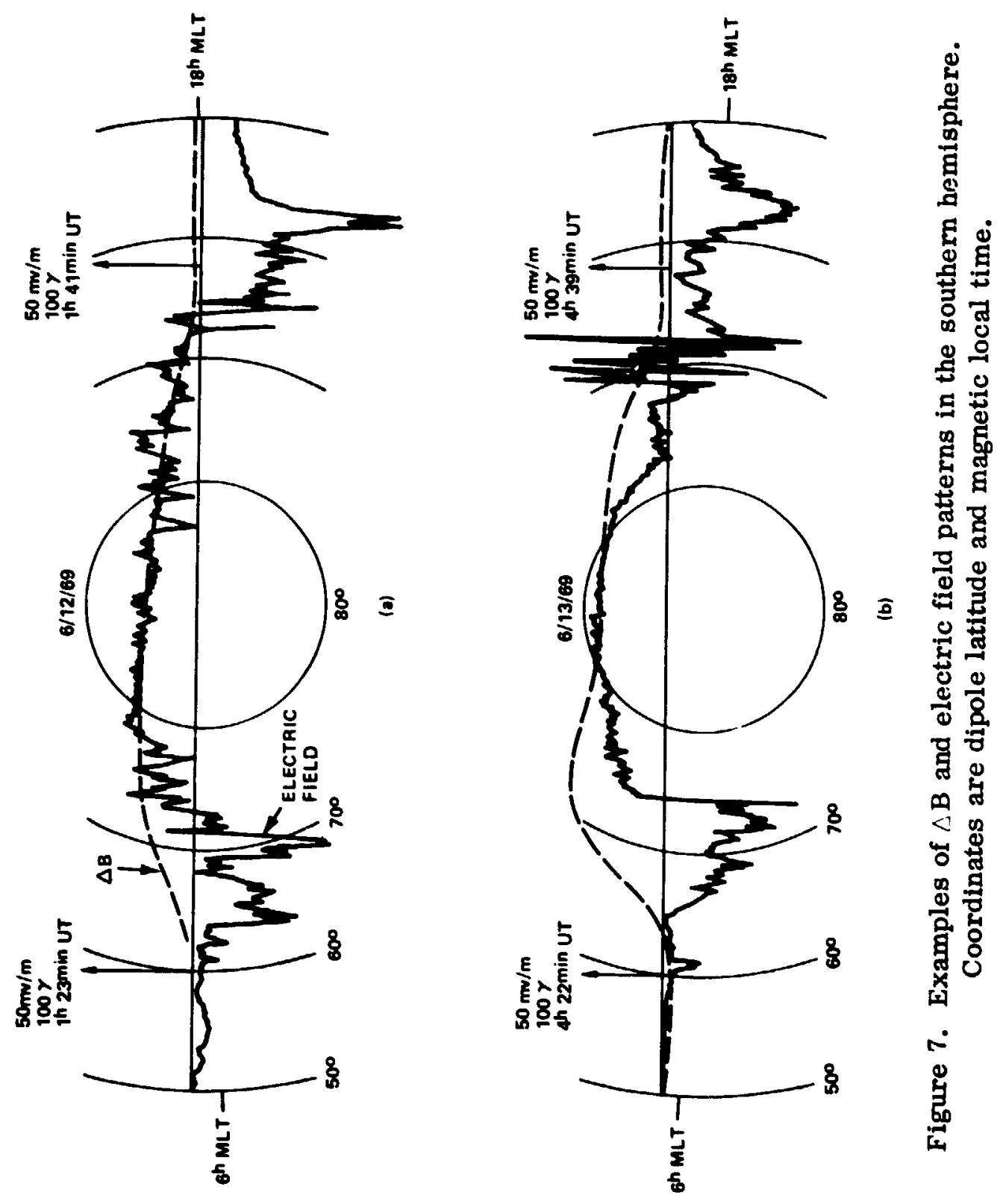

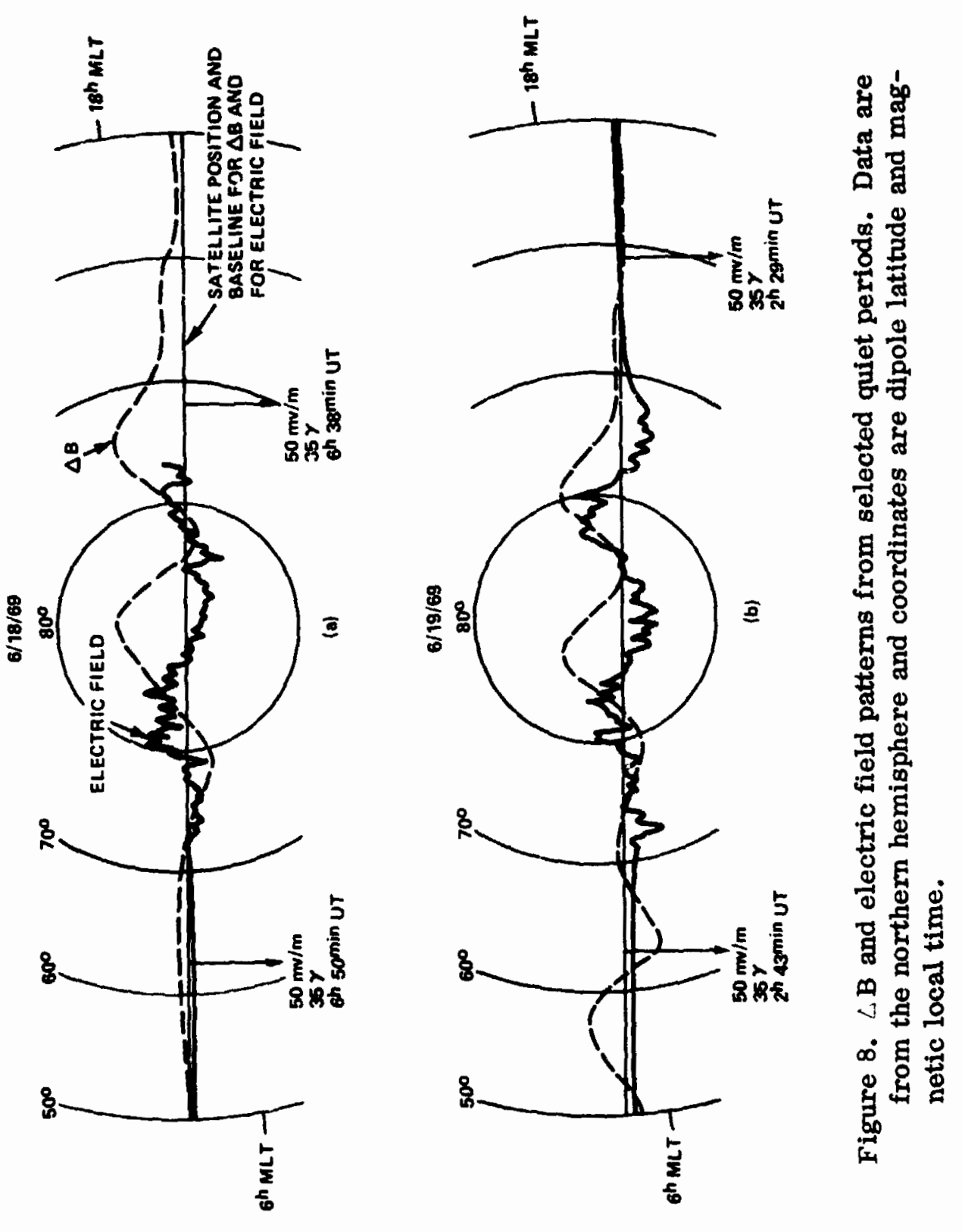


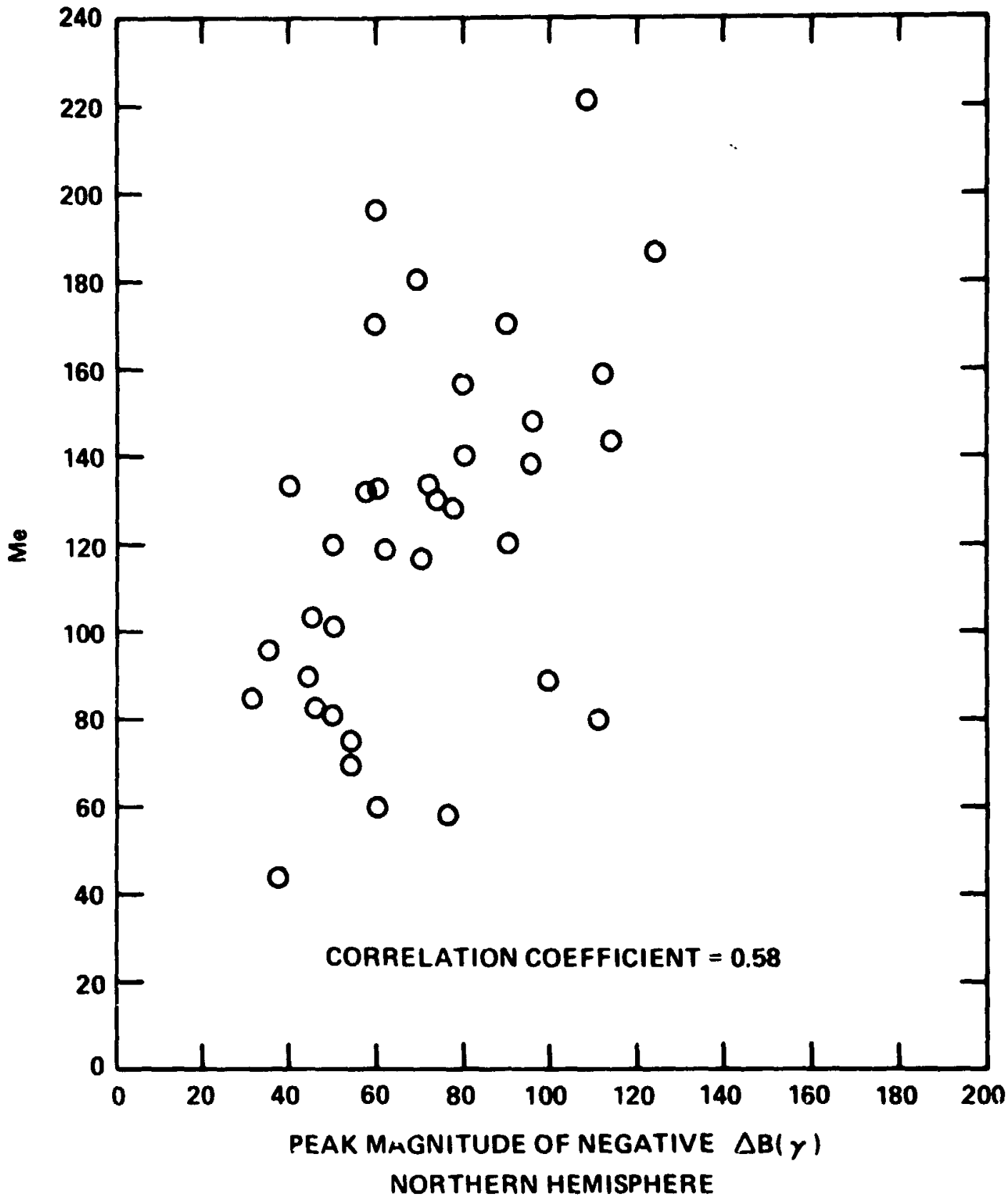

Figure 9. Scatter diagram of Me vs. the peak magnitude of negative $\Delta B$ in the northern hemisphere. 